\title{
Front Matter: Volume 11516
}

, "Front Matter: Volume 11516," Proc. SPIE 11516, Optical Technologies for Telecommunications 2019, 1151601 (22 May 2020); doi: 10.1117/12.2573024

Event: XVII International Scientific and Technical Conference "Optical SPIE. Technologies for Telecommunications", 2019, Kazan, Russian Federation 


\title{
PROCEEDINGS OF SPIE
}

\section{Optic al Tec hnologies for Telec ommunications 2019}

\author{
Vladimir A. Andreev \\ Anton V. Bourdine \\ Vladimir A. Burdin \\ Oleg G. Morozov \\ Albert H. Sultanov \\ Editors
}

\section{9-21 November 2019}

Kazan, Russian Federation

\section{Organized by}

Kazan National Research Technical University (Russian Federation)

Povolzhskiy State University of Telecommunic a tions and Informatic s(Russian Federation)

Ufa State Aviation Technical University (Russian Federation)

Published by

SPIE 
The papers in this volume were part of the technical conference cited on the cover and title page. Papers were selected and subject to review by the editors and conference program committee. Some conference presentations may not be available for publication. Additional papers and presentation recordings may be available online in the SPIE Digital Library at SPIEDigita lLibrary.org.

The papers reflect the work and thoughts of the authors and are published herein as submitted. The publisher is not responsible for the validity of the information or for any outcomes resulting from reliance thereon.

Please use the following format to cite material from these proceedings:

Author(s), "Title of Paper," in Optical Tec hnologies for Telecommunic ations 2019, edited by Vladimir A. Andreev, Anton V. Bourdine, Vladimir A. Burdin, Oleg G. Morozov, Albert H. Sultanov, Proceedings of SPIE Vol. 11516 (SPIE, Belling ham, WA, 2020) Seven-dig it Article CID Number.

ISSN: 0277-786X

ISSN: 1996-756X (electronic)

ISBN: 9781510638396

ISBN: 9781510638402 (electronic)

Published by

SPIE

P.O. Box 10, Belling ham, Washington 98227-0010 USA

Telephone +1 3606763290 (Pa cific Time)· Fax +1 3606471445

SPIE.org

Copyright $@ 2020$, Society of Photo-O ptical Instrumentation Engineers.

Copying of material in this book for intemal or personal use, or for the intemal or personal use of specific clients, beyond the fair use provisions granted by the U.S. Copyright Law is a uthorized by SPIE subject to payment of copying fees. The Transactional Reporting Service base fee for this volume is $\$ 21.00$ per article (or portion thereof), which should be paid directly to the Copyright Clearance Center (CCC), 222 Rosewood Drive, Danvers, MA 01923. Payment may also be made electronically through CCC Online at copyright.com. Other copying for republication, resale, advertising or promotion, or any form of systematic or multiple reproduction of a ny material in this book is prohibited except with permission in writing from the publisher. The CCC fee code is 0277$786 \mathrm{X} / 20 / \$ 21.00$.

Printed in the United States of America by Curran Associates, Inc., und er license from SPIE.

Publication of record for individual papers is online in the SPIE Digital Library.

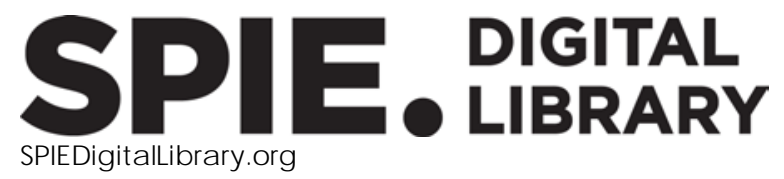

Paper Numbering: Proceedings of SPIE follow an e-First publication model. A unique citation identifier (CID) number is assigned to each article at the time of publication. Utilization of CIDs allows articles to be fully citable as soon as they are published online, and connects the same identifier to all online and print versions of the publication. SPIE uses a seven-digit CID article numbering system structured as follows:

- The first five digits correspond to the SPIE volume number.

- The last two digits indicate publication order within the volume using a Base 36 numbering system employing both numerals and letters. These two-number sets start with $00,01,02,03,04$, 05, 06, 07, 08, 09, 0A, 0B ... 0Z, followed by 10-1Z, 20-2Z, etc. The CID Number appears on each page of the manuscript. 


\section{Contents}

\section{OPTICALTEEC OMMUNICATION TECHNOLOGIES AND SYSTEMS}

1151602 Optical transport network management via machine leaming and ontology-based technique [11516-2]

1151603 Forming vortex Bessel beam for optical communication at the wavelength of $\mathbf{1 5 3 0} \mathbf{~ n m}$ [11516-7]

$1151604 \quad$ Holographic method for storage of digital information [11516-31]

1151605 The problem of provisioning optical VPN [11516-37]

1151606 Method of increasing the secrecy of radio signal transmission of RoF segment based on the use of chiped optical signals [11516-41]

1151607 Simulation of data tansmission on simple fiber acousto-optic channel [11516-42]

1151608 Leveling the risks of timing attacks based on pemutation decoding [11516-66]

1151609 The experimental impulse-radio transmission based on spectral modulation technique for highspeed communication system underthe SCRF mask regulations [11516-67]

\section{PASSIVE AND AC TIVE COMPONENTS OF OPIICAL TEEC OMMUNICATION}

11516 OA Nonlinear spiral phase plates for generation of light fields with orbital angular momentum [11516-1]

11516 OB Evaluating the influence of the refractive index dispersion of a hamonic lens on focusing properties [11516-9]

11516 OC Analysis of the rays path in the axic on taking into account their refraction and reflection [11516-10]

11516 OD Modeling the generation of a light spiral by the helical diffractive microaxic on in a three-dimensional model [11516-11]

$11516 \mathrm{OE}$ The calculation of subwa velength diffraction optical elements based on gratings with a variable period using high-performance computer systems [11516-13]

11516 OF Efficient generation of amays of c losed-packed light nings [11516-14]

11516 OG A plasmonic colour filter based on metal-insulator-metal square micro-ring cavities for visible spectrum [11516-15] 
$11516 \mathrm{OH} \quad$ Use of diffractive optical elements for beam intensity redistribution [11516-18]

11516 ol Polarization state analyzer/generator based on the three-stage polarization controller [11516-19]

11516 0] Foming of periodic three-dimensional intensity distributions based on superposition of spherical hamonics [11516-21]

11516 OK Fommation of mic rostructures in an azopolymer using paraxial vortex Gaussian beams [11516-25]

11516 OL Design features of mic rowave photonic radars [11516-30]

11516 OM Limit values of reflectivity of the periodic structure created by ultrasound in a crystal [11516-32]

11516 ON Polarization comection for propagation constant of a mode in a curved optical fiber [11516-38]

1151600 Femtosecond optical pulse propagation in an optical fiber with high birefingence [11516-40]

11516 OP Gauss-lagueme modes parameters of c urved optical fiber with coating [11516-44]

$115160 Q \quad$ Model for calc ulating the mode coupling coefficients of a curved optical fiber[11516-45]

11516 OR "Chip To Amplitude" converter on the base of erbium fiber optic amplifier for photon radio emitters controlling [11516-57]

11516 OS A concept of mic rowave photonic sensor systems based on three component addressed fiber Bragg gratings [11516-58]

$115160 T$ DAS quazi-distributed system combined with temperature measuring on addressed fiber Bragg gratings [11516-59]

11516 oU Reflection and tansmission of foc used light beam at a dielectric interface [11516-60]

11516 OV Polarization effects of light in an optical fiber [11516-61]

11516 OW Rotation of polarization vector in graded index waveguide [11516-62]

11516 0X Devices for backscattered and reflected signals processing based on integrated photonics [11516-69]

11516 oY Study of the vibration detection using few-mode optical fiber [11516-70]

$115160 Z$ OAM signal emitter based on a ring resonator [11516-71]

1151610 Mode converter based on ring resonator for integrated photonics [11516-72] 
1151611 Resonance metal-dielectric structures based on CdTe for finding the concentration of solvents in the IR region [11516-74]

1151612 Address fiber optical sensor for relative humidity measuning in a switchgear[11516-75]

1151613 Polarisation multiplexed addressed fiber Bragg grating sensors [11516-79]

\section{ONE-DIMENSION AND MULTI-DIMENSION OPICALSIG NALS DATA PROCESSING}

1151614 Mathematical modeling of the optical response from addressed fiber Bragg structure based on Lorentz function [11516-3]

1151615 Mathematical modeling of optical response of address fiber Bragg structure using Gauss function [11516-4]

1151616 Edge detection in images using energy characteristics [11516-5]

1151617 Numerical approaches to solving the Schrödinger non-linear equations system for wave propagation in an optical fiber (Invited Paper) [11516-6]

1151618 Spatial ana logue of the Huygens-Kirchhoff principle and its application for simulation of random radiating systems [11516-12]

1151619 Calculation of Karhunen-Loeve functions of given comelation function [11516-16]

$115161 \mathrm{~A} \quad$ Application of a neural network for calculating the surface relief of a different level two-zone lens with an increased depth of field [11516-17]

11516 1B Highly sensitive method for remote analysis of diagnostic images [11516-20]

11516 1C Reconstruction of images in video a nalytics systems with ultra-wide angle optics [11516-23]

11516 1D Multidimensional signals superposition of triangulation optical sensors formeasurement solid deforming [11516-26]

$115161 \mathrm{E} \quad$ Processing multidimensional signals of triangulation optical sensors for recognition railway objects [11516-27]

$11516 \mathrm{IF} \quad$ Multidimensional optical video signals supemosition formeasurement offset and rotation angle with additive and multiplicative noise [11516-28]

11516 1G Processing multidimensional signals of video surveillance for recognition railway objects [11516-29]

11516 1H 3D image file creation methods for autostereoscopic displays [11516-33] 
$115161 /$ The study of elastic streaming processing of multidimensional optical signa ls in a distributed computing environment [11516-36]

11516 1] Radar image modeling and recognition [11516-55]

\section{OPIICALNETWORKS MAINTIENANCE, CONTROLAND RESTORATION}

$115161 \mathrm{~K} \quad$ Generation of sca lable wa vefront for testing optical systems [11516-24]

$115161 \mathrm{~L}$ Lifetime prediction algonithm for an optical cable of cable link under exploitation [11516-35]

$115161 \mathrm{M}$ Prony decomposition algonithm for processing polarization reflectometry data to determine the distributions of excess optical fiber length in a cable [11516-39]

11516 iN Simple method for localization of events on traces of group of fibers from the same fiberoptic link segment [11516-43]

1151610 Fast and simple method for estimation of the insertion loss at the connection of singlemode optical fibers with contaminated femule end faces [11516-48]

$115161 \mathrm{P} \quad$ Method for estimation of Brillouin scattering signal parameters [11516-78]

\section{ADVANCED TECHNOLOGIES FOR OPIICALTELECOMMUNICATIONS}

$115161 \mathrm{Q}$ Intelligent video systems for unmanned aerial vehic les based on diffiactive optics and deep leaming (Invited Paper) [11516-56]

11516 1R Development of an expenimental stand for the prototype of the radio-over fiber telecommunication system with generation OAM signals generation in the W-band [11516-68]

1151615 Design of vortex optical fibers for RoF systems: Part l: ovenview and altemative solutions [11516-65]

$115161 T$ Design of vortex optical fibers for RoF systems: Part ll: pilot samples of chiral mic rostructured optical fibers [11516-52]

$115161 \mathrm{U}$ Recognition of vortex beams with a wavelength of $1530 \mathrm{~nm}$ in aerosol and turbulent media [11516-73]

$115161 \mathrm{~V}$ Total adaptation is an important trend of imaging systems development [11516-80]

11516 1W Multi-channel system of quantum key distribution with frequency coding based on the AMPMPMAM electro-optical sc heme [11516-81] 
PROBLPMS OF TRAINING ON OPIICALTEECOMMUNICATION SCIENCE TOPICS

$115161 X \quad$ Result-oriented projectmanagement as a soft skills development methodology forstudents studying optical communic ation systems [11516-22]

11516 1Y Project-based education as a cross-functional competences development approach [11516-34] 
Proc. of SPIE Vol. 11516 1151601-8

\section{Downloaded From: https://www.spiedigitallibrary.org/conference-proceedings-of-spie on 26 Apr 2023
Terms of Use: https://www.spiedigitallibrary.org/terms-of-use}

